\title{
The Effect of WC/C Coating on the Wear of Bevel Gears Used in Coal Mines
}

\author{
Waldemar TUSZYNSKI ${ }^{1 *}$, Marek KALBARCZYK ${ }^{1}$, Michal MICHALAK, ${ }^{1}$ \\ Remigiusz MICHALCZEWSKI ${ }^{1}$, Andrzej WIECZOREK ${ }^{2}$
}

\author{
${ }^{1}$ Institute for Sustainable Technologies, National Research Institute (ITeE-PIB), Tribology Dept., Pulaskiego 6/10, 26-600 \\ Radom, Poland \\ ${ }^{2}$ Silesian University of Technology, Faculty of Mining and Geology, Akademicka 2, 44-100 Gliwice, Poland \\ crossref $\mathrm{http}: / / \mathrm{dx}$.doi.org/10.5755/j01.ms.21.3.7263
}

Received 09 June 2014; accepted 08 November 2014

\begin{abstract}
There are many problems in the operation of spiral bevel gears; for example, difficult lubrication conditions lead to excessively high oil temperature and the risk of severe wear. Thus, the aim of this work was to check whether, by the deposition of a thin, hard, low-friction coating on the teeth flanks of spiral bevel gears, it is possible to improve the resistance to wear, reduce friction and possibly the gear vibrations.

The tribological experiments were carried out in two phases. In the first phase, a bevel gear test rig was used (laboratory testing). In the second phase, a verification test was performed using an industrial gear stand (chain conveyor) working under conditions typical of coal mines. The low-friction WC/C coating was tested. The coating was deposited on the teeth of the wheels. For reference, the uncoated pairs of spiral bevel gears were tested. In the laboratory testing, a commercial, mineral automotive gear oil of the API GL-5 performance level and 80W-90 viscosity grade was used for lubrication. For lubrication of the industrial gears, a mineral base oil of the low, VG32 viscosity grade was chosen.

The results obtained show that, by the deposition of the low-friction WC/C coating on the teeth of the wheel, the following beneficial effects can be achieved in comparison with the case of the uncoated gears: a rise in the resistance to the two forms of severe wear (scuffing and pitting), and a drop in the oil temperature (lower friction) at first tests stages. The above effects are accompanied at the first stages of the tests by an undesired, higher level of vibrations in case of the steel-WC/C material combination. However, throughout the test, the vibrations for the two material combinations became similar. Thus, the $\mathrm{WC} / \mathrm{C}$ coating can be applied to increase the wear resistance and decrease the oil temperature in the transmissions containing spiral bevel gears in, e.g., chain conveyors installed in coal mines.

Keywords: spiral bevel gear, thin coating, wear, friction, vibrations, chain conveyor.
\end{abstract}

\section{INTRODUCTION}

Bevel gears consist of cone-shaped pinions and wheels with crossing axes (the 0 offset) and are used in those drivetrains where there is a need to change the direction of torque transmission (mostly by $90^{\circ}$ ). It can be estimated that bevel gears are used, for example, in $20-30 \%$ of the speed reducers; therefore, in the present-day technology, the importance of bevel gears is high.

In spite of long-term development of the technology of bevel gear manufacturing, the producers of drivetrains equipped with bevel gears report various operational demands. One of the main issues is related to the reduction of friction, resulting in a decrease in the oil temperature and the tendency to severe wear. Such an effect may be achieved by the deposition of a thin, hard, low-friction coating on the tooth flanks of bevel gears; although, the present-day research in this area is limited mainly to spur gears $[1-8]$, and the works related to testing bevel gears are extremely rare - e.g. [9].

Addressing the above demand requires the use of a test rig capable of the friction and wear testing of bevel gears. Worldwide, there are only individual testing machines of this type, i.e. the hypoid (including bevel) gear-testing machine developed in the Gear Research Centre (FZG) at the Technical University of Munich $[10,11]$, or the test rig

\footnotetext{
* Corresponding author. Tel.: +48-48-3644241; fax: +48-48-3644765.

E-mail address: waldemar.tuszynski@itee.radom.pl (W. Tuszynski)
}

intended for aeronautics, designed at NASA Glenn Research Centre (USA) [12]. Such test rigs are not widely available, which is probably why most of the papers concerning bevel gears concentrate on only two aspects. The first is the use of mathematical modelling for the optimization of the profile and meshing conditions of bevel gears' teeth, and for the improvement of the production technology [13-15]. The second aspect is limited to case studies, focusing on the explanation of operational causes of bevel gear failures in various applications [16-18].

Apart of the test rig, in the tribological testing of bevel gears, a necessary factor is the usage of proper test methods. Unfortunately, there are no standardised tests, and the proposals of authorial methods for testing bevel gears are rarely presented in publications [10, 11].

At ITeE-PIB in Radom, a new test rig for the tribological testing of bevel gears was developed, and the authorial method for testing bevel gears was designed [19]. This paper describes their usage to check the effects of the deposition of a low-friction coating on the teeth of spiral bevel gears, e.g. the wear resistance, oil temperature, and the level of vibrations. The results obtained were verified in the transmission of a chain conveyor intended for the use in coal mines.

\section{EXPERIMENTAL DETAILS}

In the laboratory testing, specially designed test spiral bevel gears (Fig. 1) were used, which were machined in a 
high, 5th grade of precision (according to DIN 3965), from $18 \mathrm{CrNi8}$ steel, carburised up to $0.6-0.9 \mathrm{~mm}$ of depth, and tempered to 56-60 HRC of hardness. Both gear elements were machined by means of Klingelnberg's method. The T-30 Back-to-back bevel gear test rig, developed and manufactured at ITeE-PIB, was used for the testing.

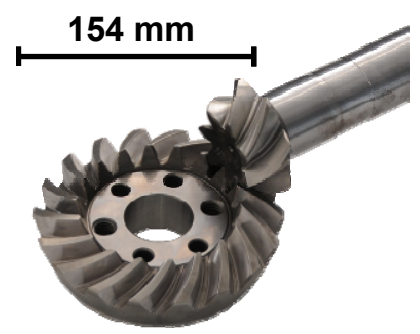

Fig. 1. Test spiral bevel gears

During the test, the loading torque was gradually increased from the $1^{\text {st }}$ to the $12^{\text {th }}$ load stage (pinion loading torque was changed from 3.3 up to $535 \mathrm{Nm}$ ); the power carried by the gears changed between 1 and $168 \mathrm{~kW}$ respectively. After the test run at a particular load stage, the teeth of the pinion were examined for the modes of wear, such as grooves and scuffing. The load stage was then increased up to the moment when the damaged area reached the area of one pinion tooth. The load stage at which the aforementioned criterion was reached is called the "Failure Load Stage" (FLS) and describes the resistance to scuffing of the tested bevel gears. During each run, the friction torque was measured. The other test parameters were as follows: pinion rotational speed $=3000 \mathrm{rpm}$, single run duration $=15 \mathrm{~min}$, initial oil temperature $=90^{\circ} \mathrm{C}$ (not stabilised during the run), and dip lubrication with the oil level up the axis of the test gears.

During the experiments, the oil temperature (using a thermocouple with its measuring point inserted in the lubricating oil) and level of vibrations were also measured (characterised by the acceleration amplitude). The last 10 temperature measurements at each load stage were averaged to give the more reliable final oil temperatures.

A mineral, automotive gear oil of API GL-5 performance level and SAE $80 \mathrm{~W}-90$ viscosity grade was used for lubrication. Such an oil is very often used for lubrication of final drives in motor vehicles, which consist of spiral bevel or hypoid gears.

In the verification testing industrial, spiral bevel gears were used, which were machined in a $9^{\text {th }}$ grade of precision (according to DIN 3965), from 18CrNiMo7 steel, carburised and tempered. Both gear elements were machined by means of Gleason's method. Such a material of gears and way of machining are typical of spiral bevel gears used in chain conveyors.

Some geometrical parameters of the test and industrial gears are compiled in Table 1.

Table 1. Comparison of the bevel gears used in the experiment

\begin{tabular}{|l|c|c|}
\hline Feature & Test gears & Industrial gears \\
\hline Number of pinion teeth & 7 & 13 \\
\hline Number of wheel teeth & 18 & 43 \\
\hline Normal module & 8.70 & 3.02 \\
\hline Normal pressure angle & $20^{\circ}$ & $20^{\circ}$ \\
\hline Mean spiral angle & $35^{\circ}$ & $30^{\circ}$ \\
\hline Shaft angle & $90^{\circ}$ & $90^{\circ}$ \\
\hline
\end{tabular}

The verification (industrial) testing was performed by means of the PAT-PPL-14/22 industrial gear stand (chain conveyor) with a $22 \mathrm{~kW}$ motor, under real conditions typical of coal mines.

The driving torque was transmitted from the electric motor via the clutch, through the transmission with spiral bevel gears, to the common shaft with chain gears, which drove the multiple chains of the conveyor. The loading torque was set by the action of the hydraulic actuator, stretching the chains in such a way that the power carried by the gears was constant $-7 \mathrm{~kW}$ (the pinion loading torque was $49 \mathrm{Nm}$, and its rotating speed was $1470 \mathrm{rpm}$ ). During the experiments, the temperature of the transmission housing near the meshing teeth (measured using an IR camera) and vibrations were measured every $25 \mathrm{~h}$ (characterised by the velocity amplitude). The test duration was $200 \mathrm{~h}$. After the test, the teeth flanks of the bevel gears were inspected for the wear traces.

For lubrication of the industrial gears, a mineral base oil of the low, VG32 viscosity grade was used, which made it possible to achieve worse conditions of lubrication than normally met in chain conveyors.

The difference between the bevel gears and conditions of the laboratory and industrial testing come from the requirements of the industry - they needed to verify the laboratory tests using such bevel gears that are applied in chain conveyors and work under conditions (loading) which appear in real service. The measurements of vibration velocity (not acceleration) came from the requirements of industrial standards, e.g. ISO 10816.

In the two experiments, the teeth flanks of the wheels were coated with the DLC, low-friction a-C:H:W coating (trade name: WC/C), deposited by physical vapour deposition (PVD). The coating thickness was about $2 \mu \mathrm{m}$.

The uncoated pairs of spiral bevel gears were used for reference. The two material combinations are schematically portrayed in Fig. 2.

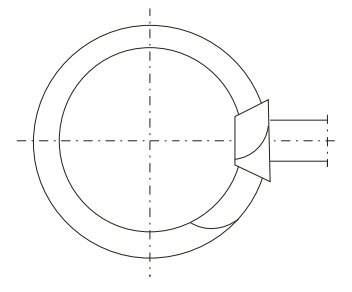

a

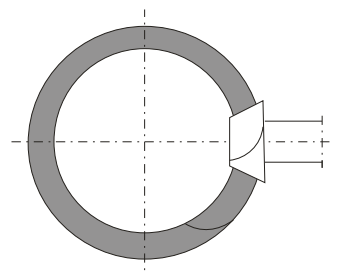

b
Fig. 2. Two tested material combinations: a - steel-steel (both bevel gears uncoated), $\mathrm{b}$ - steel-WC/C (pinion uncoated, wheel coated)

After the tribological testing, the surface of the spiral bevel gear teeth of the pinion was analysed using a Hitachi S-2460N scanning electron microscope (SEM), Thermo Electron Corporation Voyager 3050 energy dispersive spectrometer (EDS), Schaefer Q-Scope 250 atomic force microscope (AFM), and Taylor Hobson Talysurf CCI optical profilometer. The optical profilometer was employed to assess the surface roughness, defined using two parameters $S_{a}$ and $S_{z}$.

\section{RESULTS}

First, the laboratory testing using the T-30 Back-toback bevel gear test rig was performed. 
First, the resistance to severe wear called scuffing, measured by the Failure Load Stage, was tested for the two material combinations.

It was observed that when the $\mathrm{WC} / \mathrm{C}$ coating is deposited on the test wheel, the resistance to scuffing $(\mathrm{FLS}=10)$ is significantly improved in comparison with the case of the uncoated gears (FLS $=8$ ).

The comparison between the final oil temperatures at the load stages up to the $8^{\text {th }}$ for the two material combinations is shown in Fig. 3.

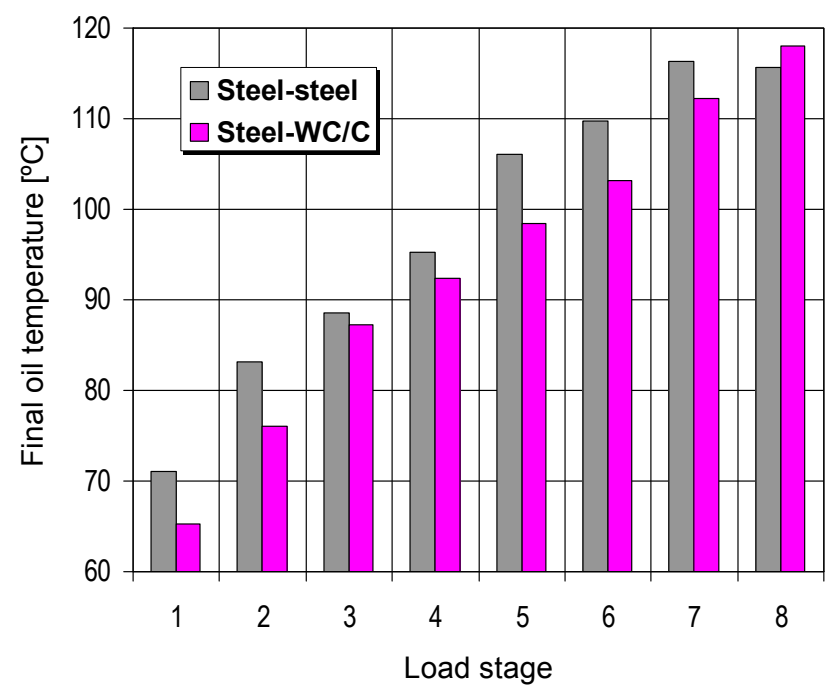

Fig. 3. Comparison of the final oil temperatures for the two material combinations at particular load stages

From Fig. 3, it is apparent that, when the WC/C coating is deposited on the test wheel, practically at each load stage (apart from $8^{\text {th }}$ load stage) the oil temperature is significantly lower than in the case of the uncoated bevel gears.

The comparison between the amplitude of acceleration of vibrations (overall level) at the load stages up to the $8^{\text {th }}$ for the two material combinations is shown in Fig. 4. At each load stage, vibrations were measured every 5 minutes.

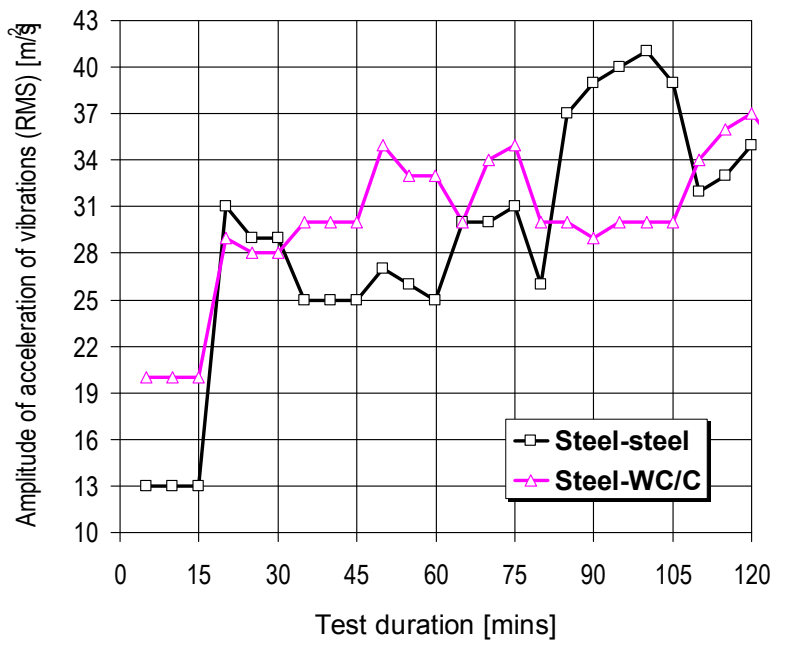

Fig. 4. Comparison of the overall level of vibrations for the two material combinations at particular load stages; run duration at one load stage $-15 \mathrm{~min}$

It can be seen in Fig. 4 that at the lowest load stages the level of vibrations for the material combination with the $\mathrm{WC} / \mathrm{C}$ coating is higher than for the uncoated bevel gears. However, at higher load stages, the levels of vibrations get closer to the moment when the bevel gear pair with the $\mathrm{WC} / \mathrm{C}$ coating produces lower vibrations than the uncoated gears (load stages 6 and 7).

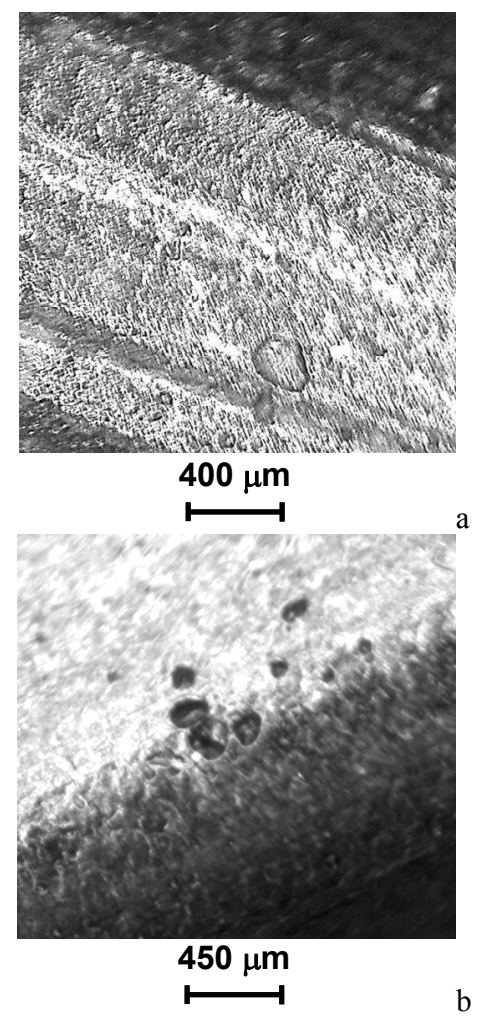

Fig. 5. Macro-scale photographs of the teeth after the test with the steel-steel material combination (both bevel gears uncoated): $\mathrm{a}$ - pinion, $\mathrm{b}$ - wheel; industrial testing
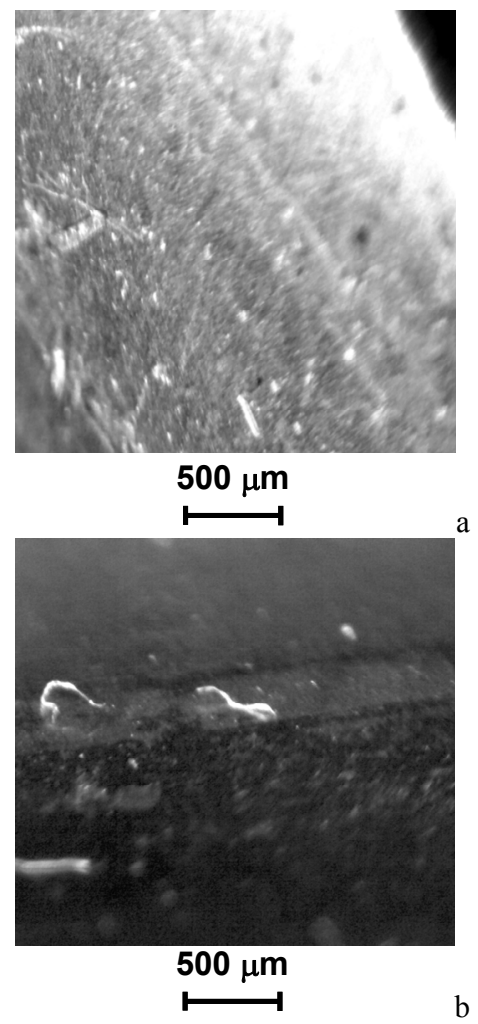

Fig. 6. Macro-scale photographs of the teeth after the test with the steel-WC/C material combination: a-pinion, $\mathrm{b}$ - wheel; industrial testing 
At the second phase of the experiment, the verification (industrial) testing, using the industrial gear stand (chain conveyor), was conducted.

The photographs of the teeth of the spiral bevel gears after the test in the two material combinations: uncoated pinion meshing uncoated wheel, and uncoated pinion meshing the WC/C-coated wheel, are shown in Fig. 5 and Fig. 6.

It can be seen from Fig. 5 that, when the both gears are uncoated, after the testing under industrial conditions, the surface fatigue wear appears on the both gears in a form of pits. This does not occur in case of the steel-WC/C material combination - Fig. 6 .

The comparison between the transmission housing temperatures measured every $25 \mathrm{hrs}$ for the two material combinations is shown in Fig. 7.

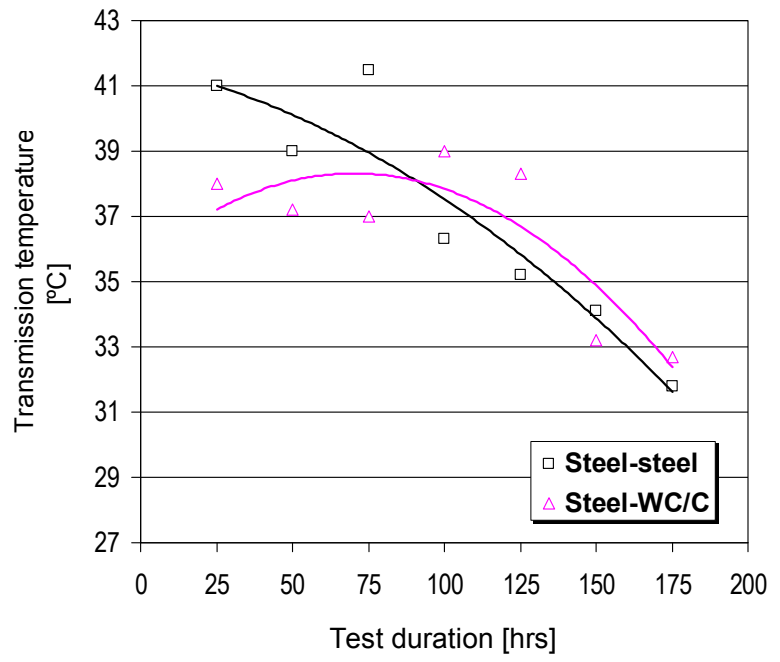

Fig. 7. Comparison of the maximum temperatures of the transmission housing, measured every $25 \mathrm{hrs}$ for the two material combinations

From Fig. 7, it is apparent that, when the $\mathrm{WC} / \mathrm{C}$ coating is deposited on the wheel, the transmission housing temperature is either significantly lower or very close to the case of the uncoated bevel gears.

The comparison between the amplitude of the velocity of vibrations for the two material combinations is shown in Fig. 8.

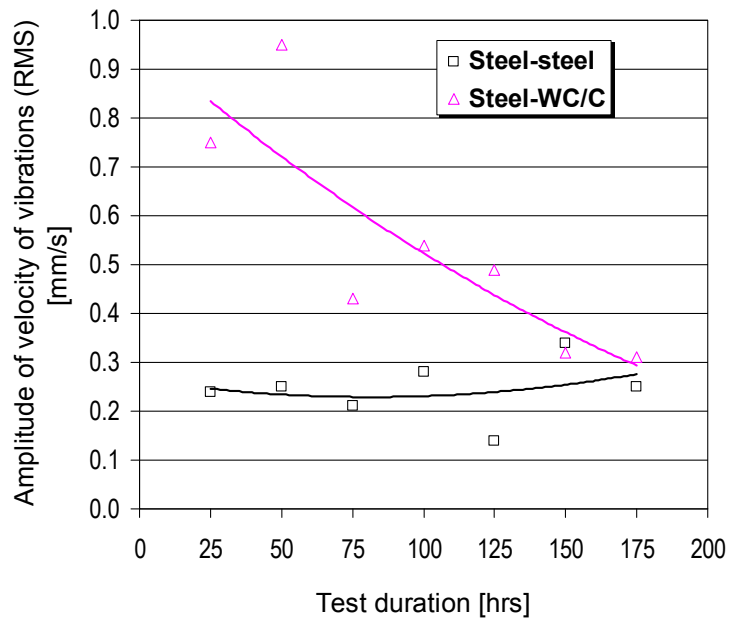

Fig. 8. Comparison of the level of vibrations for the two material combinations; vibrations characterised by the velocity amplitude at the meshing (base) frequency
It can be seen in Fig. 8 that practically during the entire test, the level of vibrations for the material combination with the $\mathrm{WC} / \mathrm{C}$ coating is much higher than for the uncoated bevel gears to equalise at the end of the test. It is interesting that the level of vibrations when one of the gears is coated continuously drops throughout the test.

\section{DISCUSSION}

In comparison to the case of the both gears uncoated, when the $\mathrm{WC} / \mathrm{C}$ coating is deposited on the test wheel, much higher resistance to scuffing is observed. This is a result of a smaller affinity in the different materials than when both of them are identical (i.e. steel-steel). Yet another phenomenon can be attributed to it. When one of the mating materials (coating) is much harder than the other one (steel), there is a reduction in the tendency to adhesive bonding, friction, hence scuffing. The same occurrence was observed when testing the coated spur gears [5]. Both phenomena also led to the reduction in the oil temperature in case of the coated wheel during the laboratory stage of the experiment (Fig. 3) apart from the $8^{\text {th }}$ load stage (explanation of this different behaviour requires a further analysis planned in the future). However, it is not a problem, as at the $8^{\text {th }}$ load stage the carried power is $75 \mathrm{~kW}$, which is much higher than in the chain conveyor, i.e. $7 \mathrm{~kW}$.

During the verification, (industrial) testing a base oil without lubricating additives was used. In this case, scuffing was not observed. This is because the working conditions in the zone of the meshing teeth were much less severe than at high load stages in the T-30 bevel gear test rig - the power carried by the gears was only $7 \mathrm{~kW}$ during the industrial tasting compared to $75-117 \mathrm{~kW}$ at the load stages 8 and 10, respectively, in the T-30 test rig. However, surface fatigue wear (pitting) was observed on the pair of the uncoated gears (Fig. 5). The reason for the pitting occurrence is described below.

When the chemically active lubricating additives are present in the oil, it leads to the formation of inorganic chemical compounds of iron with sulphur, phosphorus, zinc, and oxygen, depending on the type of the lubricating additive. For example, at the sliding or sliding-rolling movement the EP additives (based on organic S-P compounds - similar to the ones used in the API GL-5 gear oil used for lubrication of the test gears in the T-30 test rig) form e.g. iron sulphide FeS [20-23]. This is also portrayed in Fig. 9 showing EDS analyses of the concentration of sulphur and phosphorus in the surface outside and inside of the friction zone of the spiral bevel gear tooth (steel-steel material combination).
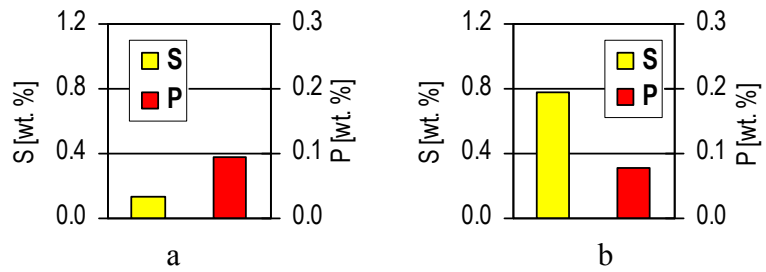

Fig. 9. EDS quantitative analyses of the concentration of $S$ and $P$ in the surface of the spiral bevel gear tooth: a - off the meshing zone, $\mathrm{b}$ - in the meshing zone; laboratory testing using T-30 test rig and steel-steel material combination 
From Fig. 9, it is apparent that, owing to the tribochemical action of the oil with the surface, chemical compounds of sulphur (e.g. FeS) with the steel surface of the gear teeth are produced. Sulphur comes from the EPtype lubricating additives in the API GL-5 gear oil.

FeS compounds, apart from hampering the creation of adhesive bonds with their five-fold lower shear strength and four-fold lower hardness than steel, facilitate shearing of the chemically modified surface asperities, reducing friction. During the industrial testing, the oil did not contain any lubricating additives. Thus, in case of the uncoated gears, friction between the meshing teeth was higher, giving a higher subsurface shear stress, which in turn brought about subsurface cracks and then pits (Fig. 5). When the low-friction $\mathrm{WC} / \mathrm{C}$ coating was deposited on the wheel, friction was reduced (the lower transmission housing temperature was observed; see Fig. 7) and the creation of subsurface cracks was mitigated - pitting was not seen in that case (Fig. 6).

As concerns the level of vibrations, both in the laboratory testing, using the T-30 bevel gear test rig at the lowest load stages (Fig. 4) and throughout the industrial testing (Fig. 8), the level of vibrations for the material combination with the $\mathrm{WC} / \mathrm{C}$ coating was higher than for the uncoated bevel gears. This is a result of the high nanohardness of the $\mathrm{WC} / \mathrm{C}$ coating $(1081 \mathrm{HV})$ resulting in a longer time needed to run it in; this is particularly apparent when observing the level of vibrations - when one of the gears is coated - continuously dropping throughout the test (Fig. 8).

However, as could be particularly seen in the industrial testing, for the material combination with the $\mathrm{WC} / \mathrm{C}$ coating, the level of vibrations much diminished. This comes from the running in of the $\mathrm{WC} / \mathrm{C}$ coating and the polishing of the uncoated gear by the abrasive action of the coating. The micro-topography of the coated surface, obtained by AFM, with visible droplet phases, which can cause abrasion of the meshing element surface, is presented in Fig. 10.

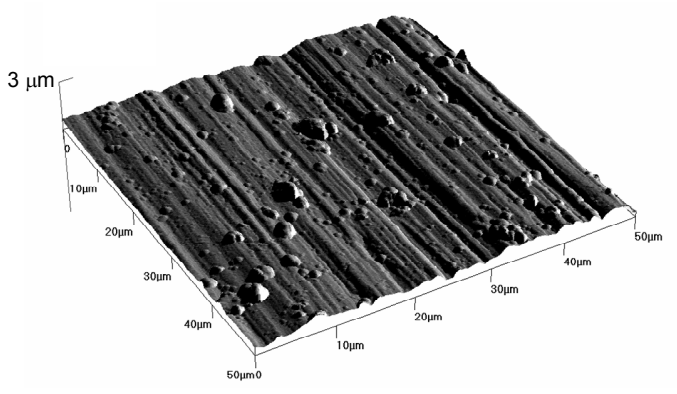

Fig. 10. Micro-topography of the WC/C coating - AFM image

In the laboratory, testing using the $\mathrm{T}-30$ test rig the area of the polishing of the uncoated pinion meshing the WC/C-coated wheel can be seen in Fig. 11.

The polished area can be recognised by the lowest surface roughness parameters $\mathrm{S}_{\mathrm{a}}$ and $\mathrm{S}_{\mathrm{z}}$. The similar behaviour was observed on the uncoated pinion teeth during the industrial testing (Fig. 12).

The potential beneficial role of the polishing of the uncoated gear meshing the $\mathrm{WC} / \mathrm{C}$-coated one is to be investigated in the future.

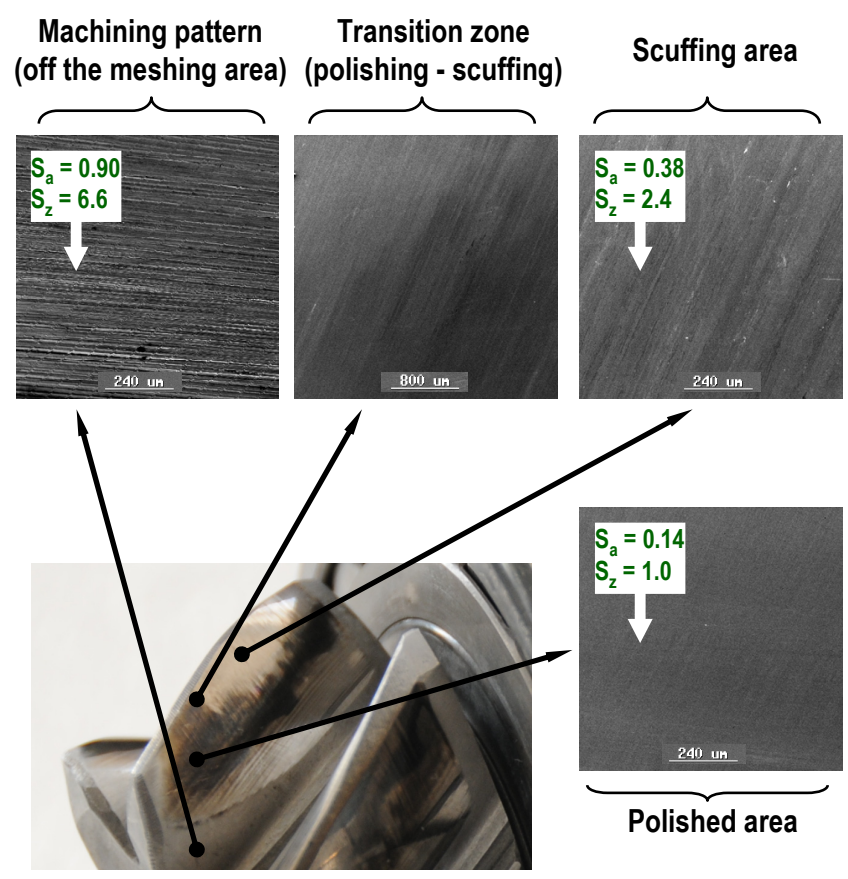

Fig. 11. SEM images of scuffed and polished areas of the pinion tooth; steel-WC/C material combination $\left(\mathrm{S}_{\mathrm{a}}\right.$ and $\mathrm{S}_{z}$ roughness parameters expressed in microns)

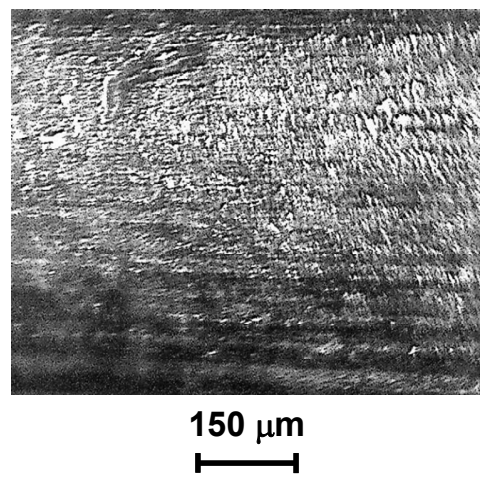

Fig. 12. Macro-scale photograph of the pinion tooth after the industrial test with the steel-WC/C material combination

\section{CONCLUSIONS}

In both the laboratory and industrial testing it was observed that by the deposition of the low-friction $\mathrm{WC} / \mathrm{C}$ coating on the teeth of the spiral bevel wheel, the following beneficial effects can be achieved in comparison with the uncoated gears (in the existing literature it was observed only for cylindrical gears):

- A rise in the resistance to the two forms of severe wear: scuffing (laboratory testing) and pitting (industrial testing); and,

- A drop in the oil temperature (in both types of testing), especially at the first stage of testing (industrial one) and the lowest loading torques (laboratory experiment), apart from the highest, $8^{\text {th }}$ load stage.

The above effects are accompanied at the first stages of the tests by an undesired, higher level of vibrations in case of the steel-WC/C material combination, observed both in the laboratory and industrial testing. However, throughout the tests, the vibrations for the two material combinations become similar. 
The proposed solution can be applied to increase the wear resistance and decrease the oil temperature in the transmissions containing spiral bevel gears. The positive results of industrial (verification) testing confirm the laboratory results.

Thus, by the deposition of the $\mathrm{WC} / \mathrm{C}$ coating on the bevel wheel, one can improve the durability and reliability of the transmissions of chain conveyors installed in coal mines.

\section{REFERENCES}

1. Kalin, M., Vižintin, J. The Tribological Performance of DLC-coated Gears Lubricated with Biodegradable Oil in Various Pinion/Gear Material Combinations Wear 259 2005: $\quad$ pp. $1270-1280$. http://dx.doi.org/10.1016/j.wear.2005.02.028

2. Martins, R. C., Moura, P. S., Seabra, J. O. $\mathrm{MoS}_{2} / \mathrm{Ti}$ LowFriction Coating for Gears Tribology International $39 \quad 2006$ : pp. 1686-1697. http://dx.doi.org/10.1016/j.triboint.2006.02.065

3. Martins, R., Amaro, R., Seabra, J. Influence of Low Friction Coatings on the Scuffing Load Capacity and Efficiency of Gears Tribology International 41 2008: pp. $234-243$.

http://dx.doi.org/10.1016/j.triboint.2007.05.008

4. Michalczewski, R., Piekoszewski, W., Szczerek, M., Tuszynski, W. The Lubricant-Coating Interaction in Rolling and Sliding Contacts Tribology International 42 2009: pp. 554560. http://dx.doi.org/10.1016/j.triboint.2008.05.001

5. Tuszynski, W., Michalczewski, R., Szczerek, M., Kalbarczyk, M. A New Scuffing Shock Test Method for the Determination of the Resistance to Scuffing of Coated Gears Archives of Civil and Mechanical Engineering (ACME) 12 2012: pp. 436-445.

6. Michalczewski, R., Piekoszewski, W., $\quad$ Szczerek, M., Tuszynski, W., Antonov, M. The Rolling Contact Fatigue of PVD Coated Spur Gears Key Engineering Materials 527 2013: pp. 77-82. http://dx.doi.org/10.4028/www.scientific.net/KEM.527.77

7. Michalczewski, R., Kalbarczyk, M., Piekoszewski, W., Szczerek, M., Tuszynski, W. The Rolling Contact Fatigue of WC/C-Coated Spur Gears Journal of Engineering Tribology 227 (8) 2013: pp. 850-860.

8. Michalczewski, R., Piekoszewski, W., Tuszynski, W., Szczerek, M. The Problems of Resistance to Scuffing of Heavily Loaded Lubricated Friction Joints with WC/C Coated Parts Industrial Lubrication and Tribology 66 (3) 2014: pp. 434-442. http://dx.doi.org/10.1108/ilt-01-2012-0001

9. Basiniuk, U. L., Levantsevich, M. A., Maksimchenko, N. N., Mardasevich, A. I. Improvement of Triboengineering Properties and Noise Reduction of Tooth Gears by Cladding Functional Coatings on Working Surfaces of Interfaced Teeth Journal of Friction and Wear 34 (6) 2013: pp. 438-443. http://dx.doi.org/10.3103/S1068366613060044

10. Winter, H., Richter, M. Scuffing Load Capacity of Hypoid and Bevel Gears. Proc. 8 JSME International Symposium "Gearing", 1975.
11. Conrado, E., Höhn, B. R., Michaelis, K., Klein, M. Influence of Oil Supply on the Scuffing Load-Carrying Capacity of Hypoid Gears Journal of Engineering Tribology 221 2007: pp. $851-858$.

12. Hadschuh, R. F. Testing of Face-Milled Spiral Bevel Gears at High-Speed and Load. NASA/TM-2001-210743 2001: pp. $1-8$.

13. Akimov, V. V. Initial Contour Optimization for Bevel Gears with Circular Teeth Journal of Machinery Manufacture and Reliability 37 (4) 2008: pp. 371-378. http://dx.doi.org/10.3103/S1052618808040092

14. Suh, S-H., Jung, D-H., Lee, E-S., Lee, S-W. Modelling, Implementation, and Manufacturing of Spiral Bevel Gears with Crown International Journal of Advanced Manufacturing Technology 21 2003: pp. 775-786. http://dx.doi.org/10.1007/s00170-002-1393-0

15. Tsai, Y. C., Hsu, W. Y. The Study on the Design of Spiral Bevel Gear Sets with Circular-Arc Contact Paths and Tooth Profiles Mechanism and Machine Theory 43 2008: pp. $1158-1174$. http://dx.doi.org/10.1016/j.mechmachtheory.2007.08.004

16. Sekercioglu, T., Kovan, V. Pitting Failure of Truck Spiral Bevel Gear Engineering Failure Analysis 14 2007: pp. $614-619$.

http://dx.doi.org/10.1016/j.engfailanal.2006.03.002

17. Fonte, M., Reis, L., Freitas, M. Failure Analysis of a Gear Wheel of a Marine Azimuth Thruster Engineering Failure Analysis 18 2011: pp. 1884-1888. http://dx.doi.org/10.1016/j.engfailanal.2011.07.009

18. Siddiqui, N. A., Deen, K. M., Zubair Khan, M., Ahmad R. Investigating the Failure of Bevel Gears in an Aircraft Engine Case Studies in Engineering Failure Analysis 1 2013: pp. 24-31.

19. Michalczewski, R., Kalbarczyk, M., Tuszynski, W., Szczerek, M. The Scuffing Resistance of WC/C Coated Spiral Bevel Gears Key Engineering Materials 604 2014: pp. 36-40. http://dx.doi.org/10.4028/www.scientific.net/KEM.604.36

20. Godfrey, D. Boundary Lubrication. In: Ku P.M., editor. Interdisciplinary Approach to Friction and Wear, Southwest Research Institute, Washington D.C., 1968, pp. 335-384.

21. Tuszynski, W. An Effect of Lubricating Additives on Tribochemical Phenomena in a Rolling Steel Four-Ball Contact Tribology Letters 24 (3) 2006: pp. 207-215. http://dx.doi.org/10.1007/s11249-006-9137-1

22. Tuszynski, W., Szczerek, M. Qualitative Discrimination between API GL Performance Levels of Manual Transmission Fluids by Comparing their EP Properties Determined in a New Four-Ball Scuffing Test Tribology International 65 2013: pp. 57-73. http://dx.doi.org/10.1016/j.triboint.2013.01.007

23. Tuszynski, W., Szczerek, M., Michalczewski, R., OsuchSlomka, E., Rogos, E., Urbanski, A. The Potential of the Application of Biodegradable and Non-Toxic Base Oils for the Formulation of Gear Oils - Model and Component Scuffing Tests Lubrication Science $26(5)$ 2014: pp. 327-346. http://dx.doi.org/10.1002/1s.1262 